\title{
Cervical Cancer Risk Factors among Female High School Students in Baguio city
}

\author{
Maqbool, Dua'a $\mathbf{J}^{1} \rtimes$ \\ George, Meryl P. ${ }^{2}$ \\ Kenduiwa, Shannize $\mathbf{C}^{3}$ \\ Saley, Rocelyn ${ }^{4}$ \\ Tactay, Carisse M. ${ }^{5}$ \\ Varghese, Sheryl P. ${ }^{6}$ \\ Avednigo, Conrad Carlos ${ }^{7}$ \\ Vina Grace Lorenz S. Honrados \\ Surendra Rapeti Naidoo ${ }^{9}$ \\ ${ }_{1,2,3,4,5,6,67,9,9}$ Saint Louis University, Baguio City, Philippines
}

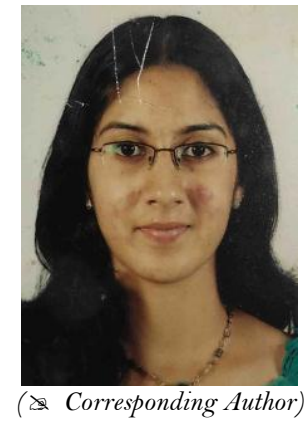

( Corresponding Author)

\begin{abstract}
Objective: To determine and correlate the prevalence of cervical cancer risk factor exposures such as smoking, sexual activity, use of condoms, contraceptives pills, and history of STIs according to age and high school year level in Baguio city high-school students, Philippines. Background: Cervical cancer is the second cause of cancer deaths among women in the Philippines and the second most frequent cancer in women ages 15-44 [1]. Methods: The risk stratification level of cervical cancer development was determined using a questionnaire adapted from Siteman Cancer Center and Barnes- Jewish Hospital and Washington University School of Medicine. A coding manual was created for each of the risk factors and the level stratification of the risk factors. The study size was computed with the use of Open Epi, Version 2, open source calculatorSSPropo, an internet based epidemiologic calculator. Results: $98.3 \%$ of the study group was classified to have much below average risk of developing cervical cancer. $1.2 \%$ of the study group was of below average risk and $0.5 \%$ of the study group was with above average risk of cervical cancer with significant relationship to age of first sexual contact and number of sexual partners. Conclusion: An increased risk of cervical cancer among these students were associated with early onset of sexual activity, increasing number of sexual partners and early parity.
\end{abstract}

Keywords: Cervical cancer, Females, Baguio, High school, Students, Philippines.

Citation | Maqbool, Dua'a J; George, Meryl P.; Kenduiwa, Shannize C; Saley, Rocelyn; Tactay, Carisse M.; Varghese, Sheryl P.; Avednigo, Conrad Carlos; Vina Grace Lorenz S. Honrado; Surendra Rapeti Naidoo (2017). Cervical Cancer Risk Factors among Female High School Students in Baguio city. World Scientific Research, 4(1): $1-9$.

History:

Received: 31 January 2017

Revised: 10 April 2017

Accepted: 12 July 2017

Published: 17 August 2017

Licensed: This work is licensed under a Creative Commons

Attribution 3.0 License $(\mathrm{cc}) \mathbf{B Y}$

Publisher: Asian Online Journal Publishing Group
Contribution/Acknowledgement: All authors contributed to the conception and design of the study.

Funding: This research is self-funded. The researchers were responsible for the choice of research design, data collection, analysis, and drafting of the manuscript.

Competing Interests: The authors declare that they have no conflict of interests.

Transparency: The authors confirm that the manuscript is an honest, accurate, and transparent account of the study was reported; that no vital features of the study have been omitted; and that any discrepancies from the study as planned have been explained.

Ethical: This study follows all ethical practices during writing. 


\section{Contents}

1. Introduction

2. Methods

3. Results.

4. Main Result

5. Discussion

\section{Introduction}

\subsection{Background/ Rationale}

Cervical cancer is the second cause of cancer deaths among women in the Philippines and the second most frequent cancer in women ages 15-44 [1]. The number of cervical cancer cases reported remains to be high with 7,277 new cases and 3, 807 deaths found in 2005 [2]. The Cebu Pilot project reports a low survival rate from the disease (5-yr survival: $51.7 \%, 10-y r$ survival: $44.54 \%)$ and this was found to be due to late diagnosis in two out of three cases [2].

Growing at an annual rate of more than $2 \%$ during the past decades, the Philippine population is estimated at more than 87 million as of 2005. Of this, 28 million are females aged 15 to 64 years old the age bracket during which cervical cancer arises (Dr. Cecilia A. Ladines-Llave). High-risk human papillomavirus (HPV) types, such as 16 and 18, are consistently identified in Filipino women with cervical cancer [3].

Factors identified to increase the likelihood of HPV infection and subsequent development of cervical cancer include young age at first intercourse, low socioeconomic status, high parity, smoking, use of oral contraception and risky sexual behaviours [3]. Risk factors for persistent infection include multiple sex partners, sex at an early age, history of sexually transmitted infections, and smoking [4].

National efforts in different countries have been made to address cervical cancer. The Philippine Department of Health (DOH) adopted from the World Health Organization (WHO) the National Cervical Cancer Prevention and Control (NCCPC) Program which according to Health Secretary Ona "addresses the cervical cancer issue in the country in three different levels: (1) promotion of healthy lifestyle, (2) early diagnosis to detect pre-cancerous lesions and other abnormalities, and (3) immediate treatment to prevent pre-cancerous lesions from developing" [5]. Included in the program's early detection of precancerous lesions and abnormalities is the use of the Papanicolaou smear. These free cervical screenings have been conducted for Filipino women ages 30-45 in participating hospitals and it has been shown to have caused a decrease in risk of the disease [2].

However, in a similar NCCPC Program in The Netherlands [6] wherein the age range for screening was 3060 years, it was found that of the women diagnosed with cervical cancer, 1/3 were outside the age range set by the screening program; these women were either younger or older than the target age range. [7] agree to this by stating that "while overall rates of cervical cancer have significantly declined with the introduction of the programmer in some countries, cervix cancer has the second incidence in genital cancers for the age group 20-24 years". Bjørge, et al. [8] observed 5\% LSIL (low-grade squamous intraepithelial lesions) prevalence among adolescents, and 7\% in women from 20 to 29 years. Sadegui, et al. [9] reviewed 194,000 cytopathological exams and observed peak prevalence of SIL (squamous intraepithelial lesions) between 20 and 24 years, supporting the hypothesis that the process begins during adolescence. Cervical cancer is a public health concern and will continue to devastate the lives of many women, families and their societies if action is not taken [10].

\subsection{Objectives}

Taking into consideration the changing sexual practices of younger women (i.e. multiple partners and earlier first intercourse) as well as incidences of pregnancy, a question therefore arises whether there is a need to reevaluate the age range of cervical cancer screening. This study aims to determine and correlate the prevalence of cervical cancer risk factor exposures such as smoking, sexual activity, use of condoms, contraceptives pills, and history of STIs according to age and high school year level. It also focuses to determine the risk stratification level of cervical cancer development in the high school students, using a questionnaire adapted from Siteman Cancer Center and Barnes- Jewish Hospital and Washington University School of Medicine [3]. 


\section{Methods}

\subsection{Study Design}

This study uses the cross sectional study design to determine the prevalence of cervical cancer risk factors and their association to cervical risk factor stratification. The study utilized questionnaires as a method of data collection. A questionnaire was created based on a cervical cancer risk factor stratification scale adapted from Siteman Cancer Center and Barnes- Jewish Hospital and Washington University School of Medicine.

A total of 438 questionnaires were distributed, however only 420 where included in the final analysis. The 18 questionnaires not included were considered invalid due to incomplete information provided by the respondents like missing age, answers to questions, etc.

The questionnaires were grouped according to age and high school year level. Cervical cancer risk factor stratification was done for each valid questionnaire with the use of a risk stratification scale adapted from Siteman Cancer Center and Barnes- Jewish Hospital and Washington University School of Medicine. The risk factor levels ranged from much below average, below average, above average, and average.

Data from the questionnaires was then tallied according to age and prevalence of risk factors in each of the age groups. A data base was created with the use of Microsoft excel. A coding manual was created for each of the risk factors and the level stratification of the risk factors. These codes where used in the creation of the database.

\subsection{Setting}

The study was conducted in Baguio City National High School, Philippines. Respondents were from $1^{\text {st }}$ to $4^{\text {th }}$ year levels. Sections from each year level, with 40-50 students, were picked at random. The questionnaires were distributed to a total of 430 female students belonging to the randomly selected sections. The respondents answered the questionnaires independently in their classrooms and this process took about 30 minutes per classroom.

\subsection{Participants}

The eligibility criterion that was followed in the study was that all participants were female high school students from Baguio City national High-school. The participants were selected at random from all year levels and the age range was from 12 to 18 years old.

\subsection{Variables}

The outcome of the study is focused on the risk stratification of Cervical Cancer as determined by the risk stratification scale adapted from the Siteman Cancer Center and Barnes- Jewish Hospital and Washington University School of Medicine. The Exposures considered were the risk factors of cervical cancer including cigarette smoking, age of coitarche, number of sexual partners, use of condom, use of OCPs, parity, previous STIs and previous pap smears.

\subsection{Bias}

Bias in this study was addressed by ensuring anonymity of the respondents. During data gathering, a possible bias that was encountered is the response bias, where the respondents may have answered the questionnaires according to how they may have thought the researchers may have wanted them to answer and not according to their own true experiences.

\subsection{Study Size}

The study size was computed with the use of OpenEpi, Version 2, open source calculator-SSPropo, an internet based epidemiologic calculator. A target sample size of 384 women with a confidence level of $95 \%$ was reached. The final sample size used was 420 female students. The sample size was randomly selected from the population of high school students. The table below (Table 1) shows the sample size for frequency in the population that was calculated in the study. 
World Scientific Research, 2017, 4(1): 1-9

Table-1. Sample Size for Frequency in a Population

\begin{tabular}{l|l}
\hline Population size(for finite population correction factor or fpc) $(N):$ & 155716 \\
\hline Hypothesized \% frequency of outcome factor in the population $(p):$ & $50 \%+/-5$ \\
\hline Confidence limits as \% of $100($ absolute $+/-\%)(d):$ & $5 \%$ \\
\hline Design effect (for cluster surveys-DEFF): & 1 \\
\hline
\end{tabular}

Sample Size(n) for Various Confidence Levels

\begin{tabular}{c|c|c|c}
\hline Confidence & Level? & Sample Size & \\
\hline $95 \%$ & & 165 & \\
\hline $80 \%$ & & 271 & \\
\hline $90 \%$ & & 670 & \\
\hline $97 \%$ & & 1076 & \\
\hline $99 \%$ & & 1500 & \\
\hline $99.9 \%$ & & & \\
\hline $99.99 \%$ & & & \\
\hline
\end{tabular}

Source: OpenEpi, Version 2, open source calculator-SSPropo,

\subsection{Quantitative Variables}

The quantitative variable in this study was age. The ages ranged from 12 to 18 years old. This was the age group chosen, as it is the onset of adolescence and sexual maturity.

\subsection{Statistical Methods}

Frequencies were calculated for each set of exposures. Correlations between the variables and risk stratifications were analyzed using p- values calculated by the Fisher Exact Test, with a confidence interval of 95\%, as the expected value of a cell in majority of the variables was $<5$. Minimum, mean and mode age for the variables were also calculated.

\section{Results}

\subsection{Participants}

The sample consisted of 420 female high school students, from year levels 1 to 4 .

\subsection{Descriptive Data}

The participants of this study were female adolescents, between the ages of 12 \& 18, studying at Baguio City National High School. Table 2 represents the distribution of study participants based on exposures and potential confounders (age, educational levels). 
World Scientific Research, 2017, 4(1): 1-9

Table-2. Study Group Distribution by Year Level, Age, And Exposures (N=420)

\begin{tabular}{|c|c|c|}
\hline & No. of Respondents & Study Population (\%) \\
\hline \multicolumn{3}{|c|}{ Year Levels } \\
\hline $1^{\text {st }}$ Years & 127 & 30.2 \\
\hline $2^{\text {nd }}$ Years & 102 & 24.3 \\
\hline $3^{\text {rd }}$ Years & 94 & 22.4 \\
\hline $4^{\text {th }}$ Years & 97 & 23.1 \\
\hline \multicolumn{3}{|c|}{ Age (Years) } \\
\hline 12 & 37 & 8.8 \\
\hline 13 & 108 & 25.7 \\
\hline 14 & 89 & 21.2 \\
\hline 15 & 102 & 24.3 \\
\hline 16 & 70 & 16.7 \\
\hline 17 & 9 & 2.1 \\
\hline 18 & 5 & 1.2 \\
\hline
\end{tabular}

Cigarette Smoking

\begin{tabular}{|c|c|c|}
\hline Yes, 1-14/Day & 35 & 8.3 \\
\hline \multicolumn{3}{|l|}{ Age of Coitarch (Years) } \\
\hline$<16$ & 7 & 1.7 \\
\hline$>/=16$ & 4 & 1.0 \\
\hline \multicolumn{3}{|l|}{ No. of Sexual Partners } \\
\hline $1-2$ & 9 & 2.1 \\
\hline$>3$ & 2 & 0.5 \\
\hline Use of Condom & 0 & $\mathrm{O}$ \\
\hline Use of Ocps & 1 & 0.2 \\
\hline \multicolumn{3}{|l|}{ Parity } \\
\hline 1 & 1 & 0.2 \\
\hline Previous Sti & $\mathrm{O}$ & $\mathrm{O}$ \\
\hline Pap Smear Awareness & 37 & 8.8 \\
\hline Previous Pap Smear & 0 & $\mathrm{O}$ \\
\hline
\end{tabular}

* OCP: Oral Contraceptive pills; STI: Sexually Transmitted infections 


\subsection{Outcome Data}

The prevalent outcome events are presented in Table 3. The risk calculated, is an estimate of the chance of ever developing cervical cancer in one's lifetime compared to an average person, of the same age and sex. $0.5 \%$ of the sample was categorized as having above average risk of cervical cancer. $1.2 \%$ was categorized as below average, while $98.3 \%$ had a much below average risk of cervical cancer.

Table-3. Risk Stratification of the Study Group

\begin{tabular}{l|l|l}
\hline Risk Stratification & Frequency & Study Population (\%) \\
\hline Much Below Average & 413 & 98.3 \\
\hline Below Average & 5 & 1.2 \\
\hline Average & 0 & 0 \\
\hline Above Average & 2 & 0.5 \\
\hline Source: Open Epi, Version 2, open source calculator-SSPropo &
\end{tabular}

\section{Main Result}

Table-4. Association between the Risk Stratification and Study Variables $(\mathrm{Ci}=95 \%)$

\begin{tabular}{|c|c|c|c|}
\hline & Much Below Average & Below Average & Above Average \\
\hline & P-Value & P-Value & P-Value \\
\hline & \multicolumn{3}{|c|}{ (Using Fisher Exact Test) } \\
\hline Cigarette Smoking & 0.1086878347 & 0.3541820887 & 0.1599045346 \\
\hline \multicolumn{4}{|l|}{ Age of Coitarch } \\
\hline$<16$ Y.O & $0.0000009419^{*}$ & $0.0000001361^{*}$ & 0.9669053302 \\
\hline$>/=16 \mathrm{Y} . \mathrm{O}$ & $0.0000113372^{*}$ & $0.0469404107^{*}$ & $0.0000681896^{*}$ \\
\hline \multicolumn{4}{|c|}{ No. Of Sexual Partners } \\
\hline $1-2$ & $0.0000000245^{*}$ & $0.0000000012^{*}$ & 0.9575519945 \\
\hline$>/=3$ & $0.0002386635^{*}$ & 0.9763041255 & $0.0000113649^{*}$ \\
\hline Use of Condom & - & - & - \\
\hline Use of Ocp & - & - & - \\
\hline Parity & $0.0166666667^{*}$ & $0.0119047619^{*}$ & 0.9952380952 \\
\hline Previous Sti & - & - & - \\
\hline Previous Pap Smear & - & - & - \\
\hline
\end{tabular}


World Scientific Research, 2017, 4(1): 1-9

Table-5. Prevalence of Associated Study Variables within Risk Stratifications

\begin{tabular}{|c|c|c|c|}
\hline & Much Below Average & Below Average & Above Average \\
\hline & Prevalence & Prevalence & Prevalence \\
\hline \multicolumn{4}{|c|}{ Age of Coitarch } \\
\hline$<16 \mathrm{Y} . \mathrm{O}$ & $0.7 \%($ Vs. $99.3 \%)$ & $80 \%$ (Vs. $20 \%)$ & - \\
\hline$>/=16 \mathrm{Y} . \mathrm{O}$ & $0.2 \%($ Vs. $99.8 \%)$ & $20 \%($ Vs. $80 \%)$ & $100 \%$ \\
\hline \multicolumn{4}{|c|}{ No. of Sexual Partners } \\
\hline $1-2$ & $1 \%($ Vs. 99\%) & $100 \%$ & - \\
\hline$>/=3$ & $0 \%($ Vs. $100 \%)$ & - & $100 \%$ \\
\hline Parity & O\% (Vs. $100 \%)$ & $20 \%$ (Vs. $80 \%)$ & - \\
\hline
\end{tabular}

Source: OpenEpi, Version 2, open source calculator-SSPropo

Table-6. Minimum, Mean and Mode Age for Exposure to Risk Factors and Outcomes

\begin{tabular}{|c|c|c|c|}
\hline & Minimum (Years) & Mean (Years) & Mode (Years) \\
\hline Cigarette Smoking & 13 & 15 & 16 \\
\hline \multicolumn{4}{|l|}{ Age of Coitarch } \\
\hline$<16$ & 14 & 14 & 14 \\
\hline$>/=16$ & 16 & 16 & 16 \\
\hline
\end{tabular}

No. of Sexual Partners

\begin{tabular}{|c|c|c|c|}
\hline $1-2$ & 14 & 14 & 14 \\
\hline$>/=3$ & 16 & 16 & 16 \\
\hline Use of Condom & - & - & - \\
\hline Use of Ocp & - & - & - \\
\hline Parity & 16 & 16 & 16 \\
\hline Previous Sti & - & - & - \\
\hline Previous Pap Smear & - & - & - \\
\hline Much Below Average Risk & 12 & 14 & 13 \\
\hline Below Average Risk & 14 & 15 & 14 \\
\hline Above Average Risk & 16 & 16 & 16 \\
\hline
\end{tabular}

Source: Open Epi, Version 2, open source calculator-SSPropo 


\section{Discussion}

\subsection{Key Results}

$98.3 \%$ of the study group was classified as having much below average risk of developing cervical cancer. Placement into this category was significantly associated with the fact that only $0.7 \%$ had their first sexual contact before age 16, while $0.2 \%$ had their first sexual contact at or after 16 years of age. Only $1 \%$ had 1-2 sexual partners while none had 3 or more. None of them had given birth.

$1.2 \%$ of the study group was of below average risk, significantly associated with the fact that $80 \%$ of them had their first sexual contact before the age of 16 years while $20 \%$ of them had their first sexual contact at or after the age of 16 years. All of them only had 1-2 sexual partners and $20 \%$ had given birth to 1 offspring.

$0.5 \%$ of the study group was with above average risk of cervical cancer with significant relationship to age of first sexual contact $(100 \%$ at or after 16 years) and the number of sexual partners $(100 \%$ with 3 or more sexual partners).

\subsection{Limitations}

Limitations were also there in the study. It was difficult to know whether or not a respondent has understood a question properly therefore affecting the accuracy of the results of the study. Also some respondents may not take the questions seriously nor answer honestly and these might affect the accuracy of the results too.

\subsection{Interpretation}

Even at the onset of adolescence, some students of this high school were demonstrating high risk health behaviours, thus increasing their chances of developing cervical cancer. An above average risk for developing cervical cancer can be found at even as young as 16 years. An increased risk of cervical cancer among these students was associated with early onset of sexual activity, increasing number of sexual partners and early parity.

$63 \%$ of sexually active students had their first sexual contact before the age of 16 years (by 14 years old). $2.1 \%$ had 1-2 sexual partners by 14 years of age, while $0.5 \%$ had 3 or more sexual partners by the age of 16 years. $0.2 \%$ had given birth to 1 offspring by 16 years of age. None of them used Condoms or Oral Contraceptive pills. None of them have had a pap smear, and only $8.8 \%$ were aware of what a pap smear was (out of which $97.3 \%$ were not yet sexually active).

Although cigarette smoking is a well-known risk factor for cervical cancer, this study revealed no association between smoking and increased risk. Despite this, caution must be taken as the onset of cigarette smoking (8.3\%) in this study was shown to be as young as 13 years of age with majority of smokers at the age of 16. Increased risks of cervical cancer, is seen, particularly among women smoking as many as 40 cigarettes daily.

Sexually transmitted infection does not seem to play a role among these students.

\subsection{Generalizability}

The exposure to cervical cancer risk factors in the sample population aged 12-18 years, stresses the need for Cervical Cancer Awareness Education and administration of HPV vaccines for cervical cancer as early as this age group. It also pushes towards further investigation as to whether or not this age group is eligible to be included to the recommended age range for the cervical cancer screening program.

\section{References}

[1] Human Papillomavirus and Related Cancers Fact Sheet, "WHO/ICO information centre on HPV and cervical cancer." Retrieved from http://apps.who.int/hpvcentre/statistics/dynamic/ico/country_pdf/PHL_FS.pdf?CFID=4715039\&CFTOKEN=78361556. [July 26, 2011], 2010.

[2] E. J. Domingo and A. V. V. Dy Echo, "Epidemiology, prevention and treatment of cervical cancer in the Philippines," Journal of Gynecologic Oncology, vol. 20, pp. 11-16, 2009. View at Google Scholar | View at Publisher

[3] Korean, "Korean society of gynecologic oncology and colposcopy Efren J. Domingo and Ana Victoria V. Dy Echo," Journal of Gynecologic Oncology, vol. 20, pp. 11-16, 2009.

[4] G. Juckett and H. Hartman-Adams, "Human papillomavirus: clinical manifestations and prevention," American Family Physician, vol. 82, pp. 1209-1213, 2000 . K. Boncocan, "DoH sets free cervical screening this may. Inquirer.net." Retrieved from http://newsinfo.inquirer.net/breakingnews/nation/view/201 10503-334343/DoH-sets-free-cervical-cancer-screening-this-May. [August 14, 2011 ], 2011. 
[6] R. P. D. Bie, H. C. Vergers-Spouren, L. F. A. G. Massuger, A. G. Siebes, M. R. J. Salet-Van Der Pol, J. E. M. Vedder, W. J. G. Melchers, J. Bulten, and R. L. M. Bekkers, "Patients with cervical cancer: Why did screening not prevent these cases?," American Journal of Obstetrics and Gynecology, vol. 205, pp. 64-66, 2011. View at Google Scholar | View at Publisher

[7] Jayasinghe and Garland in Moorland, Cancers related to human papilloma virus inadolescent females found in cancer in female adolescents. New York: Nova Science Publishers, Inc, 2008.

[8] T. Bjørge, A. Gunbørud, F. Langmark, G. Skacre, and S. Thoresen, "Cervical mass screening in Norway - 510,000 smers a year," Cancer Detection and Prevention, vol. 18, pp. 463-470, 1994. View at Google Scholar

[9] S. Sadegui, E. Hsieh, and S. Gunn, "Prevalence of cervical intraepithelial neoplasia in sexually active teenagers and young adults," American Journal of Obstetrics \& Gynecology, vol. 148, pp. 726-729, 1984. View at Google Scholar $\mid$ View at Publisher

[10] D. E. Bloom, E. T. Cafiero, E. Jané-Llopis, S. Abrahams-Gessel, L. R. Bloom, and S. Fathima, The global economic Burden of noncommunicable diseases. Geneva: World Economic Forum, 2011. 